\title{
IMIGRAÇÃO JAPONESA: PARTICIPAÇÃO ECONÔMICA DA COLÔNIA JAPONESA EM PRESIDENTE VENCESLAU
}

\author{
Sandra Rodrigues Dias Soares ${ }^{1}$, José Libório Vilione ${ }^{2}$ \\ ${ }^{1}$ Emeja Professor Gerson Constante de Oliveira. ${ }^{2}$ Faculdade de Presidente Venceslau - UNIESP/FAPREV. E-mail: \\ san.rds@hotmail.com
}

\section{RESUMO}

A emigração e imigração, fatores que levaram pessoas para mais variados países em busca de melhoria de vida, busca pela oportunidade de ganhar dinheiro e voltar para seu lugar de origem, no caso da imigração japonesa no Brasil demonstra a mobilidade deste povo por vários estados, principalmente no estado de São Paulo, descendo para o oeste, tendo a ferrovia como incentivo de povoamento, chegando a Presidente Venceslau e fazendo parte do surgimento desta cidade, contribuindo no âmbito econômico, social e cultural, assim como outros imigrantes que aqui já estavam. No início vieram para trabalhar nas lavouras de café, pouco depois foram adquirindo lotes de terras, abrindo matas virgens. Mesmo estando longe de sua pátria se esforçam para manter sua cultura construindo escolas e associações como forma de preservação de costumes. Para pesquisar o objeto que é a participação econômica da colônia japonesa em Presidente Venceslau, com ênfase no período de 1920 a 1945, utilizamos bibliografias, jornais e artigos.

Palavras-chave: Presidente Venceslau. Colônia Japonesa. Economia.

\section{JAPANESE IMMIGRATION: ECONOMIC PARTICIPATION OF JAPANESE COLONY IN VENCESLAU PRESIDENT}

\begin{abstract}
Immigration and emigration, factors that have led people to most several countries looking for life improvement, the searching of the opportunity to make money and to return for their place of origin, in this case the Japanese immigration in Brazil shows the mobility of this people in various states, mainly in São Paulo state, going to the west, and the railroad as an incentive for settlement, and arriving in Presidente Venceslau and being part of the appearing of this city, contributing in the economic, social and cultural scope, as well as other immigrants who have already been here. In the beginning, they have come to work in coffee farming; shortly after, they have acquired lots of land, opening virgin forests. Even far away of their homeland, they have striven to keep their culture, building schools and associations as a way to preserve the costumes. To search for the object which is the economic participation of the Japanese colony in Presidente Venceslau, emphasizing on the 1920-1945 period, we will use bibliographies, newspapers and articles.
\end{abstract}

Key Words: Presidente Venceslau. Colony Japanese. Economy. 


\section{INTRODUÇÃO}

Por observarmos a clara evidência da presença marcante de orientais em Presidente Venceslau, surge a necessidade de se fazer uma pesquisa histórica. Portanto, voltamos nosso olhar para o período de 1920 a 1945, quando famílias pioneiras de imigrantes japoneses chegam e se agregam aos brasileiros e demais estrangeiros que se encontram no município pelo mesmo fito, ganhar dinheiro com muito trabalho e voltar para sua pátria.

Iniciamos nosso trabalho nos remetendo ao longínquo Japão, tão fantasiado pelos ocidentais que de certa forma generaliza a realidade com os mitos e faz com que viva em nosso imaginário um ethos cristalizado de um Japão constituído de cerejeiras, samurais e gueixas, o que não corresponde aos fatos históricos, de um Japão forte que luta pela transformação rompendo com a era Edo presente no período feudal, fechado para o ocidente, iniciando um novo tempo com a chegada da era Meiji aberta para a industrialização. Em seguida escrevemos sobre a saga destes imigrantes pelo país, com notória aceitação pelo Estado de São Paulo e o norte do Paraná nas fazendas de café, mas eles estiveram presentes também em outros estados brasileiros. Vão descendo da região de Campinas para zonas até então consideradas sertão, que recebeu o nome de "Novo Oeste", onde que na sua chegada já encontram os mineiros e muitos imigrantes europeus desbravando a floresta nativa, terras com extensos cafezais ávidos pela mão de obra necessária e urgente. Com o advento da ferrovia o progresso torna-se mais próximo. E por fim nos embrenhamos na história local, que preserva nuances entre os cidadãos venceslauenses.

É possível encontrar notas do sucesso na agricultura, no ano 1939 em diante, o grande incentivo para a criação do bicho da seda e da hortelã que se intensifica no período da guerra, surgindo vários alambiques de óleo mentol, tendo grande participação dos nipônicos, sendo que estas atividades já eram conhecidas por muitos no Japão.

O objetivo deste trabalho é entender como pessoas originárias de terra tão distante, culturalmente tão diferente e intrigante se adaptam, constituem famílias e contribuem economicamente, participando automaticamente no desenvolvimento da cidade prestando serviços e ofertando emprego.

\section{METODOLOGIA}

Este trabalho foi realizado através de pesquisas bibliográficas, artigos, jornais e documentos locais, dando ênfase à participação econômica da colônia japonesa. 
RESULTADO

Após observação do fragmento da história de alguns membros da sociedade nipônica que permaneceram no início de Presidente Venceslau, notou-se disposição para várias atividades, no campo, na cidade, no esporte e na dedicação a língua japonesa. Trabalharam e viveram o seu tempo intensamente dando cada um a sua parcela de contribuição econômica e cultural.

\section{DISCUSSÃO}

No momento em que o Japão rompe com o feudalismo e inicia o capitalismo surgem várias modificações no meio social e econômico, onde os mais afetados são os trabalhadores rurais, passam a enfrentar grandes dificuldades, como não conseguirem pagar os altos impostos sobre a terra, ocasionando o êxodo rural. Muitos vão para a cidade, porém as indústrias não conseguem absorver a todos. Muitos dos que iam para a cidade tornavam-se pequenos comerciantes e artesãos, mas era impossível concorrer com a produção industrial e com as novas tecnologias, levando muitos a dificuldades financeiras.

Todos estes fatores obrigavam os japoneses a emigrar para outros países em busca de dinheiro. De outro lado havia o interesse por vários países de receber imigrantes para dar sustentação na nova economia vigente. ${ }^{1}$

Como alternativa o governo Japonês permite a saída de seus súditos para outros países, com uma nova política para diminuir a crise demográfica. ${ }^{2}$ E finalmente Japão e Brasil caminham para um acordo concreto que vai ser firmado efetivamente com a chegada do navio Kasato Maru aos 18 de junho de 1908, trazendo a bordo 781 japoneses.

Porém alguns fatores colaboraram com a imigração japonesa, entre esses, estava o descontentamento dos imigrantes europeus que carregavam o sentimento de engodo pelos contratantes de mão de obra como salários baixos e maus tratos, quando protestavam eram taxados de baderneiros.

Diante desses fatores, volta à tona os debates sobre a imigração de asiáticos, sendo que em 24 de setembro de 1892 foi aprovado o projeto de Monteiro de Barros onde determinava a entrada no país de qualquer povo asiático desde que tivessem uma reputação ilibada ou que não respondesse por nenhum crime em seu país. ${ }^{3}$ Negociações para finalmente se concretizar a imigração japonesa, o governo paulista contratou 3 mil japoneses em caráter experimental, assinando um contrato com a Empire Emigraton Company em 6 de novembro de 1907. É claro que

\footnotetext{
${ }^{1}$ HANDA, Tomoo. Memórias de um imigrante japonês no Brasil. São Paulo; T.A. Queiroz. Editor Ltda, 1980, p.99

${ }^{2}$ DEZEM, Rogério. Matizes do amarelo. Intolerância, étnica \& intolerância política. São Paulo: Humanitas, 2005 , p. $132-133$.

${ }^{3}$ NOGUEIRA, Arlinda Rocha: A abertura da imigração no Japão. In: Uma Epopéia Moderna, 80 anos de imigração japonesa no Brasil / Comissão de elaboração da História dos 80 anos da imigração japonesa do Brasil - São Paulo: Hucitec, 1992, p. 42.
} 
havia outro interesse por parte do governo paulista, o desenvolvimento de um comércio entre Brasil e Japão, exportando o café através do Convênio de Taubaté de 1906, desta forma se concretiza a imigração japonesa com a chegada do navio Kasato Maru no porto santista em 18 de junho de $1908 .{ }^{4}$

A história cafeeira paulista dá início nas margens do rio Paraíba, os autores Kiotani e Yamashiro fazem referência a Caio Prado Jr., em uma citação sua "O vale do Paraíba tornou-se assim um grande centro condensador de lavouras e de população; em meados do século XIX reúne-se aí a maior parcela da riqueza brasileira". ${ }^{5}$

Mas o esplendor de sucesso dura pouco tempo devido ao esgotamento do solo, isto afeta toda a região e as cidades ao seu redor, provocando um retrocesso econômico e social, originando outras especulações como se direcionar para o oeste e norte do estado. Outro fator importantíssimo é o desenvolvimento das estradas de ferro que contribuem com o desbravamento por todo o seu percurso, dando impulso ao progresso e o surgimento de novas cidades, levando pessoas para povoar regiões antes nem imaginadas por eles um dia conhecer. Os imigrantes fazem parte dessa história, entre eles os japoneses.

A procura por terras férteis para a lavoura do café faz com que as pessoas avancem em direção do chamado novo oeste ou extremo oeste, muitos fugiam das regiões de geadas e davam preferência a lugares de temperaturas mais amenas, mesmo que o solo fosse mais fraco.

E assim começou o processo de povoamento, os mineiros são pioneiros, além dos fazendeiros outros são atraídos pela ambição de ganhar dinheiro, muitos se utilizavam de maneiras lícitas, outros nem tanto, como é o caso dos grileiros.

A estrada de ferro beneficiou o povoamento na região da Alta Sorocabana como em outras também, trouxe o desenvolvimento, ao lado do seu serpentear iam surgindo lugarejos, vilas e mais a frente se tornariam cidades.

No ano de 1921, foi construída a estação de trem da Sorocabana em terras ainda em meio à floresta, dando início ao vilarejo chamado Coroados devido à grande quantidade de índios Kaingangs ou Caingangues, logo depois batizado por Perobal, por possuir muita árvore que oferecia a madeira peroba.

Havia uma agência de corretores da Cia Mendes Campos Filho, que tinha um procurador e representante Álvaro Coelho, os russos ficam instalados na Colônia Veado e Colônia Lambiano (1925), os alemães na Aymoré e Água da Colônia e os húngaros na Colônia Arpad (1923).

\footnotetext{
${ }^{4}$ Ibdem, p.55

${ }^{5}$ KIYOTANI, Masuji; YAMASHIRO, José. Do kasato- Maru até a década de 1920. In: Uma Epopéia Moderna, 80 anos de imigração japonesa no Brasil / Comissão de elaboração da História dos 80 anos da imigração japonesa do Brasil - São Paulo: Hucitec, 1992, p.74. 
Segundo D'Incao os japoneses chegam a Presidente Venceslau na década de 1920, com cinco famílias inicialmente e vão se instalar no Córrego do Veado, logo depois chegam outras famílias dando origem às colônias e bairros que compreende Marabá Paulista e Campinal. Se utilizando das palavras de Célia Sakurai, D'Incao reforça que os japoneses é um povo que mais consegue lutar contra as adversidades por possuírem um ethos cultural o Gambarê que significa suportar o insuportável, estes são os únicos a construírem clubes e escolas na zona rural. ${ }^{6}$

Segundo o relatório fornecido pelo presidente da Associação Recreativa Esportiva e Agrícola (AREA), as primeiras famílias que chegam são: Hashiyama, Ueda, Matsumoto, Myamoto e Otsuka, vieram trabalhar nas fazendas de café e com o tempo foram adquirindo terras e desenvolvendo lavouras diversas como algodão, milho, feijão, batata e amendoim, dando trabalho para várias pessoas, pois neste tempo era necessária muita mão de obra, não existia a mecanização.

Esta região vive momentos intensos no desenvolvimento econômico, com o trabalho, com a madeira que era abundante e passando pelo ciclo do café. Os mineiros são os primeiros a chegar à região dando vida ao novo oeste, no caso de Presidente Venceslau nos anos de 1920 a 1940, há a presença marcante de imigrantes de origem européia e asiática.

As colônias eram semelhantes às agrovilas e com recursos próprios fundavam as associações chamadas de Kaikan, cooperativas, fundo de ajuda mútua, escolas primárias. A maioria dos japoneses tinha como destino a zona rural, mas havia alguns que preferiram investir na zona urbana, como a família Matsuura que possuíam um armazém, escolas de corte e costura e um dentista Reizo Horimoto que possuía um consultório odontológico itinerante no seu próprio automóvel.

É interessante observar que os imigrantes chegam a Presidente Venceslau depois de terem passado por várias regiões, alguns vem para trabalhar no café, muitos vem atraídos pelo preço baixo da terra em relação a outras regiões de terra roxa, mais férteis, porém aqui as geadas quase que não existem. Outra observação são os japoneses pertencentes ao vizinho município de Piquerobi, que se relacionam com Presidente Venceslau economicamente, estudam e participam das associações das colônias japonesas venceslauense, quase como integrante desta comunidade.

\footnotetext{
${ }^{6}$ D'INCAO, Maria Ângela; NASCIMENTO, Luís Eduardo Passos. Presidente Venceslau uma região, a cidade e sua gente. Presidente Venceslau. Letras à margem, 2005, p. 14. 
Em pesquisa a Memória da Imigração foi possível identificar apenas uma família com destino direto à Presidente Venceslau, representada por Saburo Kano, com chegada ao Porto de Santos em 27 de setembro de 1938 no vapor La Plata Maru da Província de Fukushima. ${ }^{7}$

Nos jornais da década de 1940, já se falava na produção do bicho da seda, onde relata o bom momento do mercado, que o Brasil não produz o suficiente e precisa importar de outros países. No transcorrer de nossa pesquisa percebemos a existência de um grande desenvolvimento econômico que não ficava só na criação do bicho da seda, mas também em outras fontes de trabalho com agregação de valores, como as empresas compradoras de casulos que os transformavam em fios, que por sua vez davam emprego para as fiandeiras.

A hortelã foi outra cultura que teve importância econômica neste período, em uma publicação diz que é uma planta rendosa que está entusiasmando os lavradores de Presidente Venceslau, até então era desconhecida, mas agora já existem interessados, pois acreditavam ser lucrativa.

O óleo de mentol também faz parte dos produtos da Ásia, que em consequência da guerra deixava de ser vendido para o maior comprador Estados Unidos, que consome 350 toneladas ao ano. O Brasil neste momento tenta suprir esta demanda, que pode produzir de 150 a 200 litros de óleo por alqueire paulista com alto teor total de 70 e $85 \%$.

Observamos a colaboração dos imigrantes com o desenvolvimento de Presidente Venceslau no Jornal Tribuna Livre, em uma coluna semanal denominada Ação Nikkei, escrita pelo senhor Muneyuki Funada, com o objetivo de manter a memória dos antepassados. Entre eles:

Zenji Yoshihara nasceu em 01 de março de 1927, na Província de Fukuoka, Japão. Desembarcou no Porto de Santos em 1935, [...], adquiriu a primeira área de terra de dez alqueires no bairro da Figueira em Presidente Venceslau, onde se produziu amendoim, feijão, algodão e milho, $[. . .]^{8}$

Outro exemplo de participação de japoneses no desenvolvimento econômico de Presidente Venceslau, além de incentivar a prática desportiva entre os jovens.

Kakuichi Okada nasceu em 22 de junho de1907 na província de Aichi - Japão, [...] desembarcou no Porto de Santos, em 13 de julho de 1919. Em 1928, [...], a família de Kakuichi consegue adquirir uma propriedade em Piquerobi, [...], onde cultivou arroz, feijão, milho, batata, rami, bicho de seda, algodão e amendoim. Em 1932 kakuichi com 25 anos perde o pai, [...], teve de assumir o lugar dele, [...], foi um dos fundadores de Sinen-kai (associação de jovens) para a integração de jovens nikkeis da época, [...]. Entre 1940 e 1946, sempre trabalhando com seus irmãos, adquirem um caminhão zero $\mathrm{Km}$, para

\footnotetext{
Documento obtido no arquivo público do Estado de São Paulo: livro 161 , p. $116 . \quad$ Disponível em: <<http://www.arquivoestado.sp.gov.br/livros_estrangeiros_formularioLivros.php〉> acesso 27 abr 2014.

${ }^{8}$ Jornal tribuna Livre, 12/11/2005. Ano VII, $n^{\circ} 0.960$, p. 04. Acervo do senhor Muneyuki Funada. 
transportar os produtos da região, e instalaram o primeiro posto de abastecimento em Presidente Venceslau, o conhecido Posto Okada.[...]. ${ }^{9}$

Outro colaborador na atividade rural e desportiva é o senhor Kanjiro Oda,

... nasceu na província de Hiroshima, 23 de agosto de 1913, vem com seus pais para o Brasil no ano de 1914. Após passarem por várias localidades mudam-se para Piquerobi, onde compram 20 alqueires de terra na Chave Lopes, próximo de Presidente Venceslau, após forte geada perdem os pés de café e começam a cultivar algodão, batatinha e hortelã, em 1932 começa a participar da Associação Japonesa de Presidente Venceslau se dedicando ao esporte de atletismo, se destacando e conseguindo boas colocações. ${ }^{10}$

Ainda neste sentido, Massao Horie, grande produtor que alcança o título de maior produtor de batata inglesa em Presidente Venceslau.

Massao Horie nasce no Japão, na Província de Ibaraki, em 22 de março de 1925, [...]. [...] desembarcando no Porto de Santos, em 22 de março de 1926. [...], [...]. Mudou-se para Presidente Venceslau em 1928, fixaram residência na Fazenda Santa Sofia, onde trabalharam na formação de cafezais [...]. Vencido o contrato de quatro anos de formação de cafezais na Fazenda Santa Sofia, [...], seus pais compram o primeiro pedaço de terra, [...]. Participou ativamente da Associação de Jovens da Colônia (Seinenkai), [...]. Com o falecimento de seu pai Massao assumiu a responsabilidade de chefe da família Horie, e juntamente com seus irmãos trabalharam incansavelmente nas lavouras de algodão, amendoim, hortelã, e foi considerado o maior produtor de batata inglesa de Presidente Venceslau, [...]. Cultivou também bicho de seda. ${ }^{11}$

Porém os japoneses não ficaram restritos à economia rural, tiveram sua participação no desenvolvimento urbano de Presidente Venceslau e região, neste sentido o senhor Takakiti Shirassu se diferencia da maioria dos seus compatriotas, ele se dedica aos trabalhos na zona urbana como comerciante e professor.

Takakiti Shirassu nasceu no Japão, Província de Hiroshima, no dia 2 de janeiro de 1898.

[...], desembarcando no Porto de Santos em 25 de maio de 1914, [...] em 1931, Takakiti chegou a Presidente Venceslau, depois de passar por Santo Anastácio, onde tinha uma farmácia e concomitantemente era professor da língua japonesa. Em Presidente Venceslau continuou a exercer o comércio de farmácia e ao mesmo tempo lecionando japonês, [...]. Houve época em que se dedicou a profissão de fornecedor de lenha. [...], presente nos principais acontecimentos, inclusive na coordenação do programa radiofônico "Momento Oriental" na antiga ZYH-7. ${ }^{12}$

\footnotetext{
${ }^{9}$ Jornal Tribuna Livre, 22 de outubro de 2005. Ano VII, no 0.943, p. 04.

${ }^{10}$ Jornal Tribuna Livre, 17 de setembro de 2005. Ano VII, n 0.917, p. 04.

${ }^{11}$ Jornal Tribuna Livre. 02 de setembro de 2005. Ano VII, no 0.907, p. 04.

12 Jornal Tribuna Livre, 08 de outubro de 2005. Ano VII, no 0.932, p. 04.
} 


\section{CONCLUSÃO}

Nasce Presidente Venceslau onde fervilhava o desejo de progresso, entre os imigrantes, os japoneses chegam à década de 1920 dando sua contribuição. Demonstrando uma tímida presença econômica urbana e acentuada participação econômica na agricultura.

Faço aqui algumas observações relevantes à continuação de atividades que ainda permanecem até os dias atuais como a Associação Recreativa Esportiva e Agrícola (AREA), fundada em 18 de junho de 1928, participando da divulgação da culinária japonesa muito apreciada pela população local, como também mantendo sua escola de língua japonesa e atividade esportiva.

Para preservação da memória, vários pioneiros foram homenageados dando nomes de ruas, praças, bairros, escolas e na comemoração de 100 anos de imigração japonesa no Brasil é aprovado um decreto Lei $\mathrm{n}^{\circ} 239$ de 2008, com o escopo de denominação de um viaduto no km $619+300$ m do município de Presidente Venceslau (sobre a Rodovia Estadual Raposo Tavares), que foi sancionado pela Assembléia Legislativa do Estado de São Paulo onde este passa a ser denominado "Viaduto da Imigração Japonesa".

\section{REFERÊNCIAS}

A Gazeta, 1939 a 1944, Presidente Venceslau.

Arquivo público do Estado de São Paulo: livro 161, p. 116. Disponível <<http://www.arquivoestado.sp.gov.br/livros_estrangeiros_formularioLivros.php >>. Acesso $27 / 04 / 2014$.

DEZEM, Rogério. Matizes do amarelo. Intolerância, étnica \& intolerância política. São Paulo: Humanitas, 2005.

D'INCAO, Maria Ângela; NASCIMENTO, Luís Eduardo Passos. Presidente Venceslau uma região, a cidade e sua gente. Presidente Venceslau. Letras à margem, 2005, p. 14.

HANDA, Tomoo. Memória de um imigrante japonês no Brasil. São Paulo: T.A Queiroz. Editor Ltda, 1980.

Jornal Tribuna Livre, 1998 a 2015, Presidente Venceslau.

KIYOTANI, Masuji; JOSÉ, Yamashiro: Do Kasato Maru até a década de 1920. In: Uma Epopéia Moderna, 80 anos de imigração japonesa no Brasil / Comissão de elaboração da História dos 80 anos da imigração japonesa do Brasil. São Paulo: Hucitec, 1992, p.63.

NOGUEIRA, Arlinda Rocha: A abertura da imigração no Japão. In: Uma Epopéia Moderna, 80 anos de imigração japonesa no Brasil / Comissão de elaboração da História dos 80 anos da imigração japonesa do Brasil - São Paulo: Hucitec, 1992, p. 42. 